\title{
Liquid-supported Dentures: A Boon for Atrophic Ridges
}

\author{
${ }^{1}$ Sharayu Nimonkar, ${ }^{2}$ Vikram Belkhode, ${ }^{3}$ Pranali Nimonkar, ${ }^{4}$ Seema Sathe, ${ }^{5}$ S urekha G odbole
}

\begin{abstract}
Prosthetic rehabilitation of atrophic ridges is always a challenging task, since treatment modalities, such as ridge augmentation and implant-retained complete dentures are not always feasible due to health reasons, cost factor, etc. This article describes a case report of constructing a liquid-supported denture using a simple, innovative laboratory procedure, which provides a soft tissue surface as compared with conventional complete dentures and added comfort to underlying tissues. It helps in preservation of residual ridge resorption by optimal distribution of masticatory forces and gives adequate retention stability and support.
\end{abstract}

Keywords: Cyanoacrylate, Glycerine, Liquid-supported dentures, Polyethylene sheet.

How to cite this article: Nimonkar S, Belkhode V, Nimonkar P, Sathe S, Godbole S. Liquid-supported Dentures: A Boon for Atrophic Ridges. Int J Recent Surg Med Sci 2017;3(2):119-123.

Source of support: Nil

Conflict of interest: None

\section{INTRODUCTION}

The only thing constant in life is "change" and the residual ridge is not an exception to this.

The reduction of residual ridge is a chronic, progressive, irreversible, and cumulative process, the exact etiology of which is unknown. Constant pressure is considered as one of the causes for the bone resorption.

Treatment options for patients with resorbed ridges include ridge-augmentation surgeries, implant-retained prosthesis, or conventional denture prosthesis. Treatment modality depends on patient's state of health and need, condition of residual ridge, financial capacity, and skill of the dentist. ${ }^{1}$

In most situations, surgical intervention is not possible and conservative management is the treatment of choice.

An ideal denture base should continuously adapt to the mucosa and, hence, should be flexible to reduce the stress concentration. At the same time, it should be ridgid

\footnotetext{
${ }^{1-5}$ Senior Lecturer

1,2,4,5 Department of Prosthodontics, Datta Meghe Institute of Medical Sciences, Wardha, Maharashtra, India

${ }^{3}$ Department of Oral Surgery, Datta Meghe Institute of Medical Sciences, Wardha, Maharashtra, India

Corresponding Author: Sharayu Nimonkar, Senior Lecturer Department of Prosthodontics, Datta Meghe Institute of Medical Sciences, Wardha, Maharashtra, India, Phone: +919158900453 e-mail: snimonkar@gmail.com
}

enough to support the teeth during function. Obviously, these properties cannot be combined in one material. To address these issues, tissue conditioners and soft liners were introduced. All these materials are only temporary provisions because they lose plasticity over a period of time. They also encourage candida growth, thus requiring several relining visits and follow-ups. ${ }^{2}$

Therefore, a more permanent solution for such cases can be liquid-supported dentures, which provide both plastic and elastic recovery. This case report describes a technique of fabrication of liquid-supported dentures for atrophic maxillary edentulous residual alveolar ridges. ${ }^{3}$

\section{CASE REPORT}

An 80-year-old male patient reported to the Sharad Pawar Dental College, Sawangi, Wardha, India, for prosthetic rehabilitation of the edentulous maxillary and mandibular arches. Clinical examination revealed highly atrophic maxillary and mandibular ridges (Figs 1 and 2) with dull aching pain over the ridges on palpation. Orthopantograph showed highly resorbed maxillary and mandibular ridges. To prevent further resorption, the liquid-supported denture was planned in this case.

All the clinical and laboratory steps until the flasking of the denture were carried out meticulously in the conventional manner. On the master cast, the $1.5-\mathrm{mm}$ thick polyethylene sheet (Drufolen) was vacuum heat pressed (Biostar vacuum forming machine, Scheu-dental, Germany) at six atmospheric pressure (Fig. 3). At the time of packing, this 1.5-mm thick sheet was incorporated in a denture (Fig. 4) with the extensions $2 \mathrm{~mm}$ short of the borders and excluding the extensions in the posterior palatal seal area. The thickness of the denture was kept at 3 $\mathrm{mm}$. The denture was packed along with this polyethylene sheet in a heat-cured acrylic resin (leucitone, Dentsply) as shown in (Fig. 5) and was processed using a long curing cycle. The denture was finished, polished, and delivered. The patient was asked to use the denture for 2 weeks.

After 2 weeks, the denture was converted to liquidsupported denture. Additional silicon putty impression (Aquasil, Densply) of tissue surface of the denture was made as shown in (Fig. 6) and poured in dental stone to get the junction of the denture-based resin and the polyethylene sheet, and the junction was marked on the cast. A new $0.5-\mathrm{mm}$ thick polyethylene sheet was vacuum pressed on this new cast and was cut until the junction was marked on the cast as shown in (Fig. 7). 


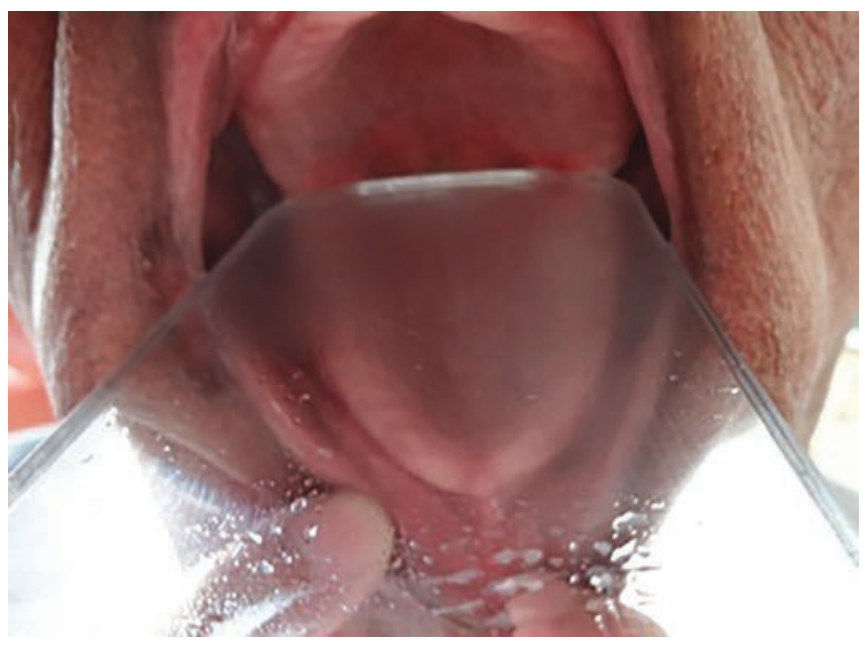

Fig. 1: Severely resorbed maxillary ridge

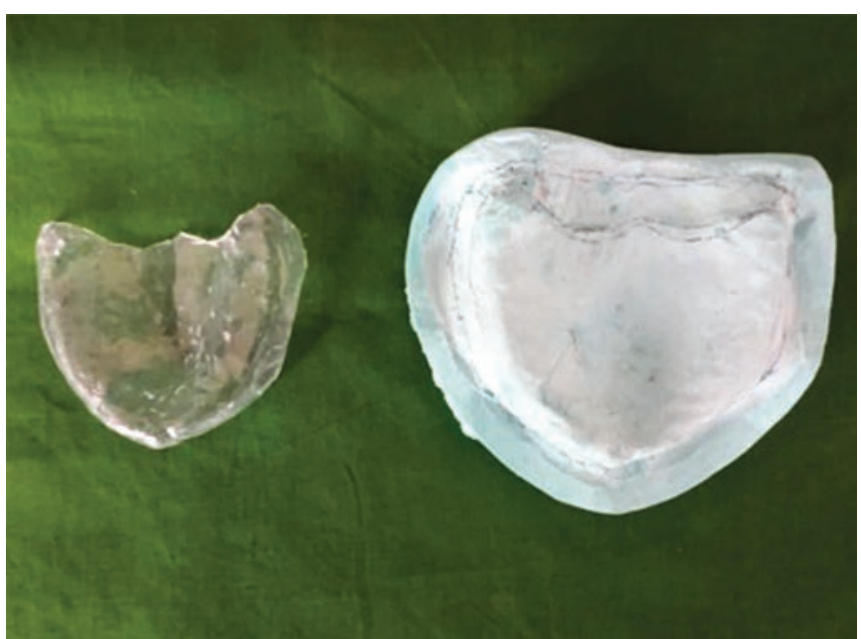

Fig. 3: Polyethylene sheet vacuum pressed over master cast

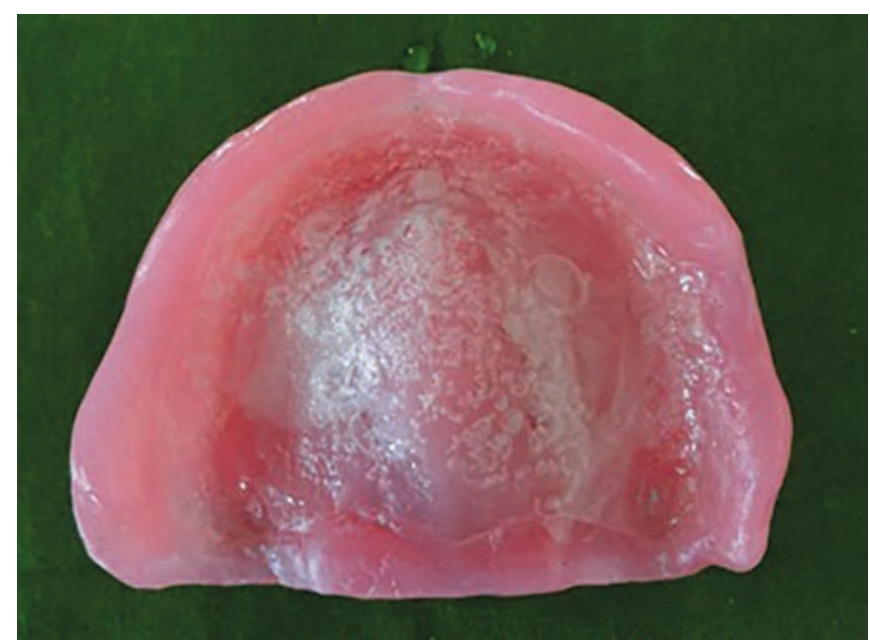

Fig. 5: Processed maxillary denture with 1.5-mm-thick polyethylene sheet

The 1.5-mm thick sheet was removed as shown in (Fig. 8) and two inlets were made by bur in the denture buccally in the molar region as shown in (Fig. 9). The $1.5-\mathrm{mm}$ thick sheet was replaced by a $0.5-\mathrm{mm}$ thick

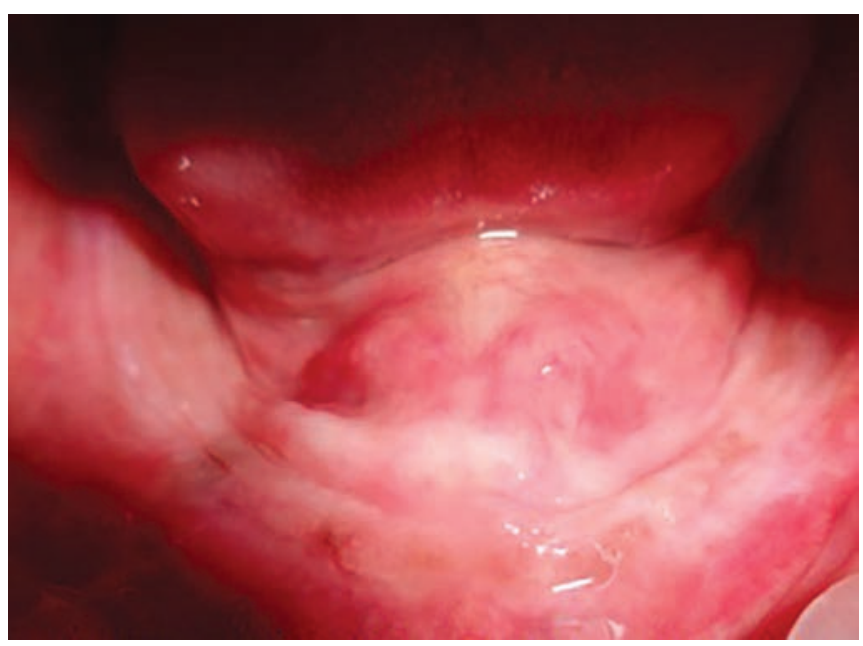

Fig. 2: Severely resorbed mandibular alveolar ridge

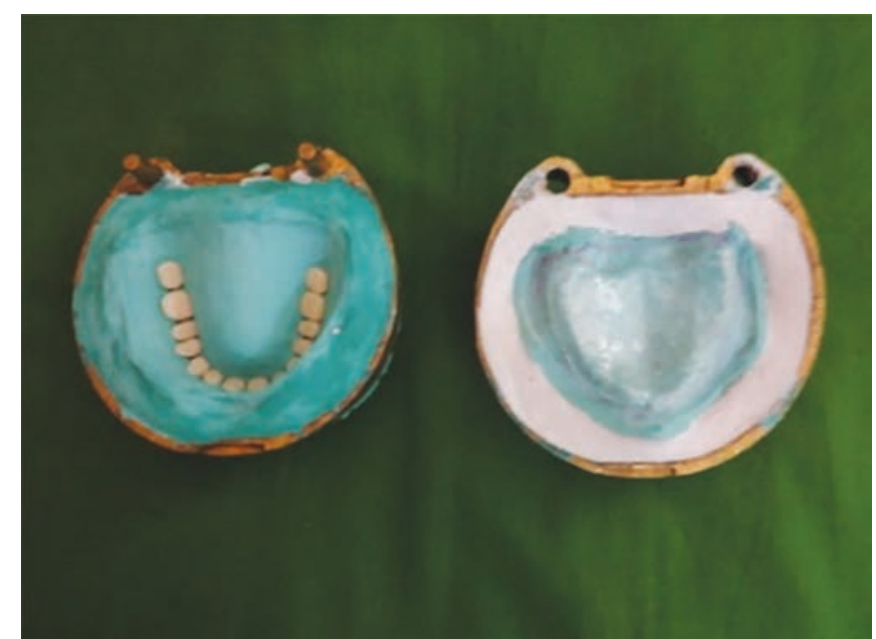

Fig. 4: Polyethylene sheet $1.5 \mathrm{~mm}$ thick incorporated at the time of packing

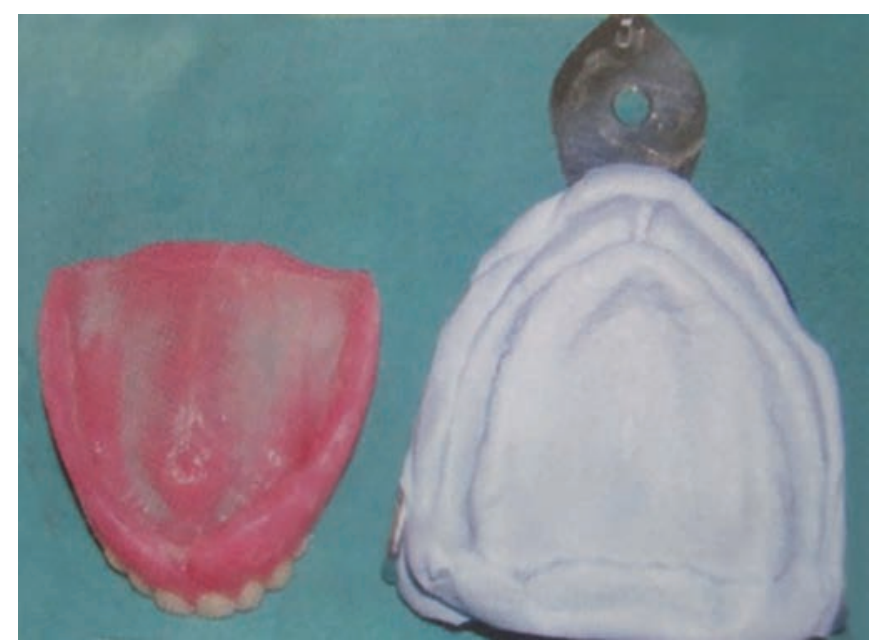

Fig. 6: Impression of the tissue surface of maxillary denture in putty impression material

polyethylene sheet. The sheet was fixed as shown in (Fig. 10) with medical-grade cyanoacrylate adhesive and sealed with light cure dental adhesive (Prime and Bond NT ${ }^{\mathrm{TM}}$, Dentsply Caulk, Milford, DE). The seal was 


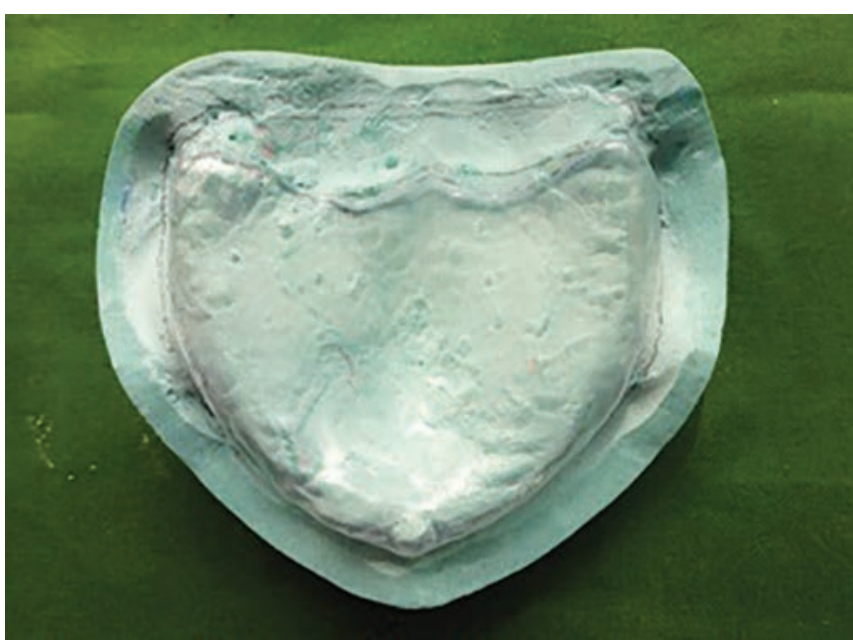

Fig. 7: New 0.5-mm-thick polyethylene sheet adapted over the new cast

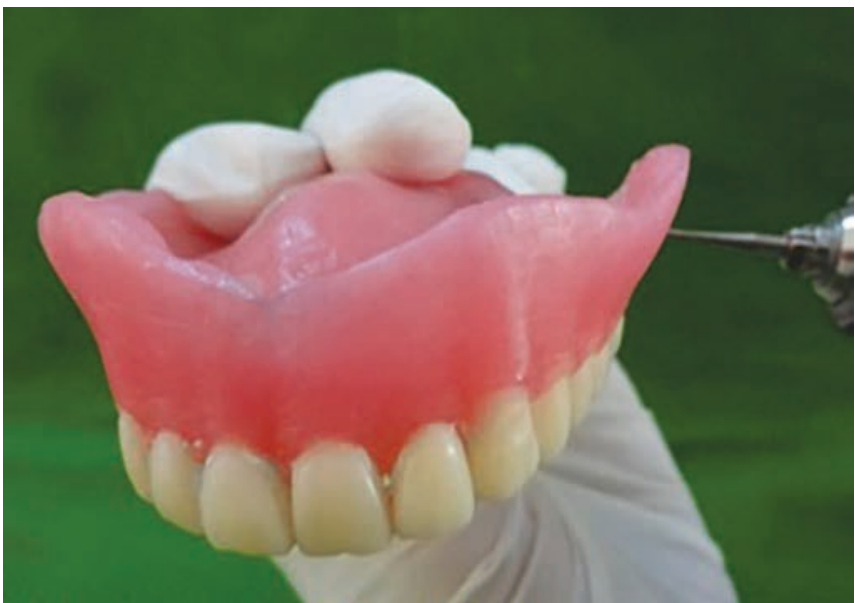

Fig. 9: Holes made for glycerin insertion

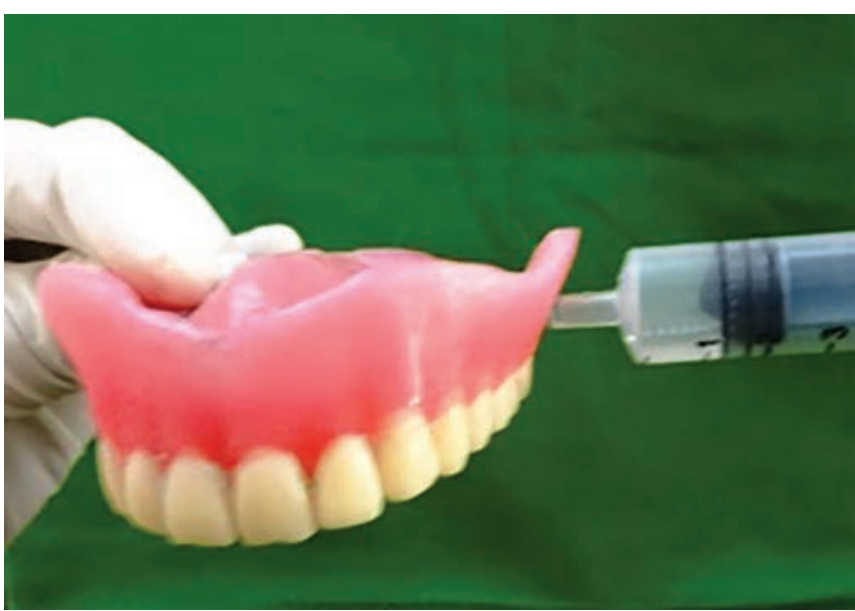

Fig. 11: Incorporation of glycerin

checked for leakage by blowing air around it. The space created due to the difference in the thickness of the sheet was occupied by liquid glycerin. Glycerin was filled through the inlets with the help of syringe as shown in (Fig. 11). Once filled completely, one inlet was closed using cold cure acrylic resin. Vertical dimensions of the

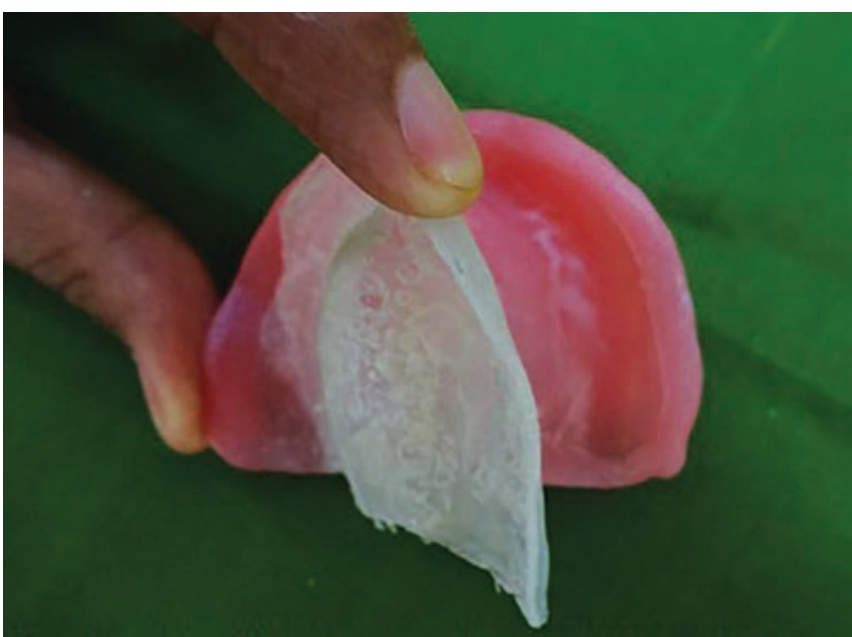

Fig. 8: A 1.5-mm-thick polyethylene sheet removed for $0.5 \mathrm{~mm}$ thick sheet

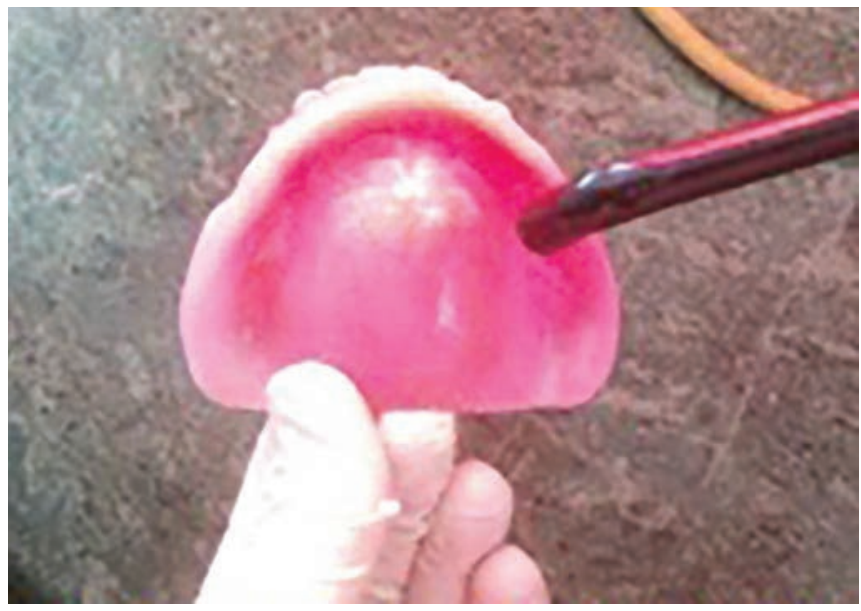

Fig. 10: A $0.5 \mathrm{~mm}$ sheet sealed with light-cured dental adhesive

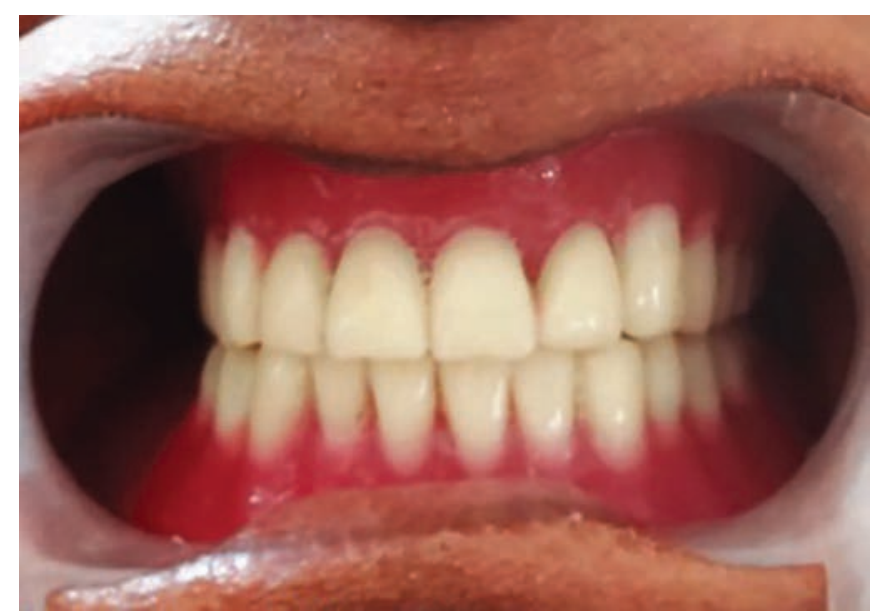

Fig. 12: Denture insertion frontal view

occlusion were adjusted in the patient's mouth and then the other inlet was closed.

The denture was finished, polished, as shown in (Figs 12 and 13) and delivered as shown in (Figs 14 and 15). Postdenture instructions were given. In case the liquid leaked out, the patient was instructed to inform 


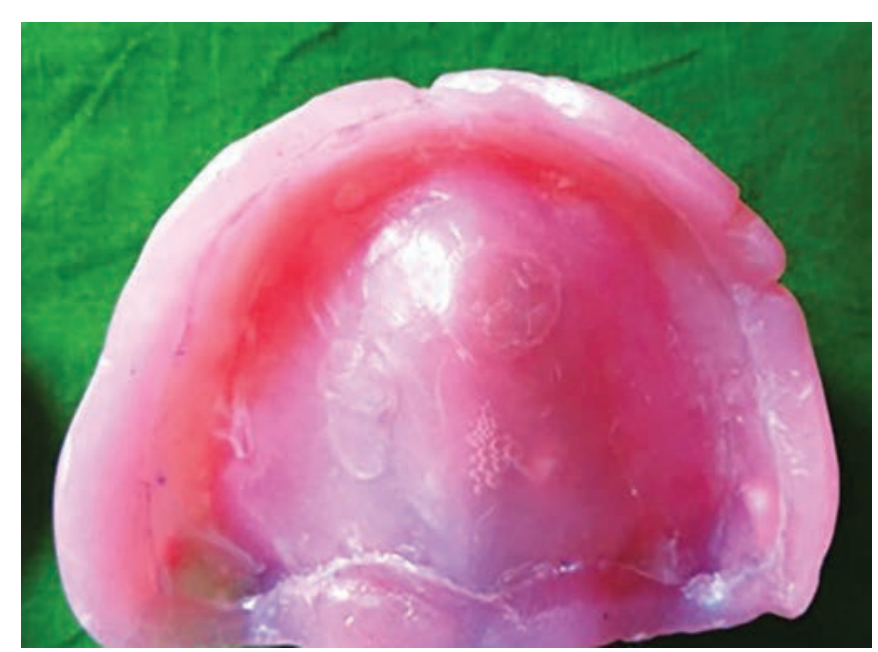

Fig. 13: Liquid-supported denture

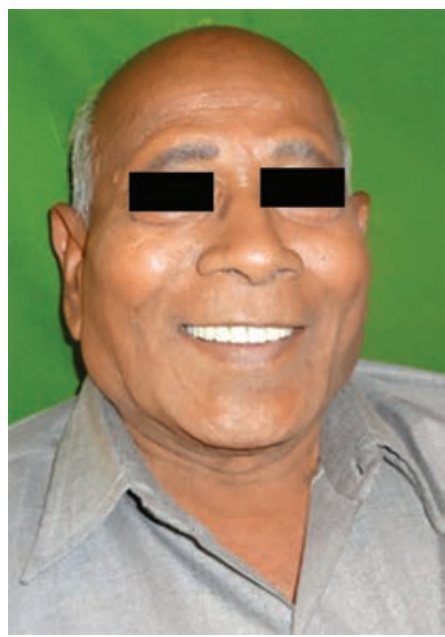

Fig. 15: Post insertion view

dentist and get it refilled and sealed. The stone cast was preserved so as to repair the denture in case the sheet ruptured. Follow-ups were carried out a day after and then on weekly basis.

\section{DISCUSSION}

Liquid-supported denture is designed for long-term preservation of bone and soft tissues. When no forces are applied, it acts like a soft liner, and when the masticatory forces are applied, the forces are distributed over a large surface and, thus, optimize stress distribution and prevent overloading of supporting tissues and also pressure spots. ${ }^{4}$

When the vertical forces are applied, the base adapts to the modified form of mucosa due to hydrodynamics of the liquid and the stability retention and support are improved. Liquid-supported dentures are also indicated in bruxers to reduce overloading and bone resorption. ${ }^{5}$

The polyethylene sheet used in this case is soft and flexible that acts as a soft liner, is dense to prevent leakage, and protects against candidal contamination and biomechanical

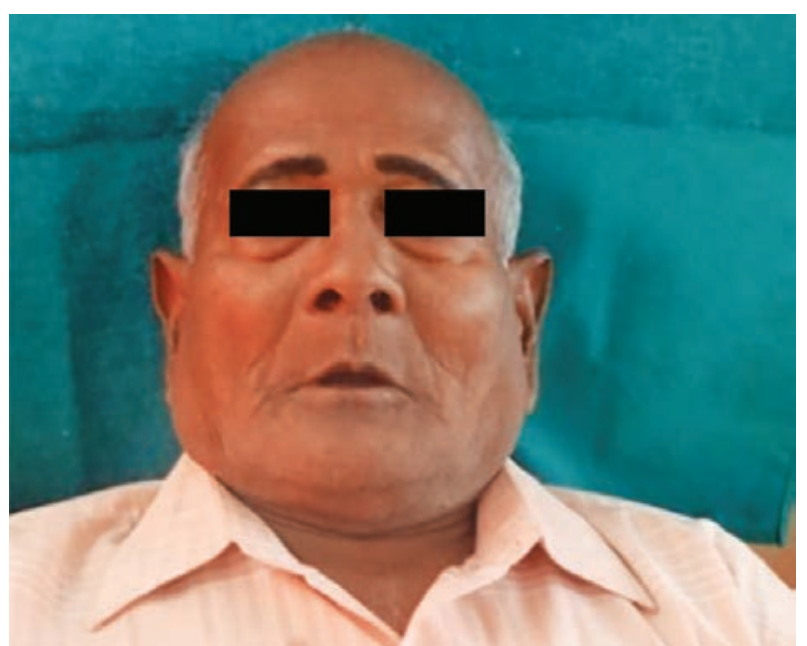

Fig. 14: Preoperative view

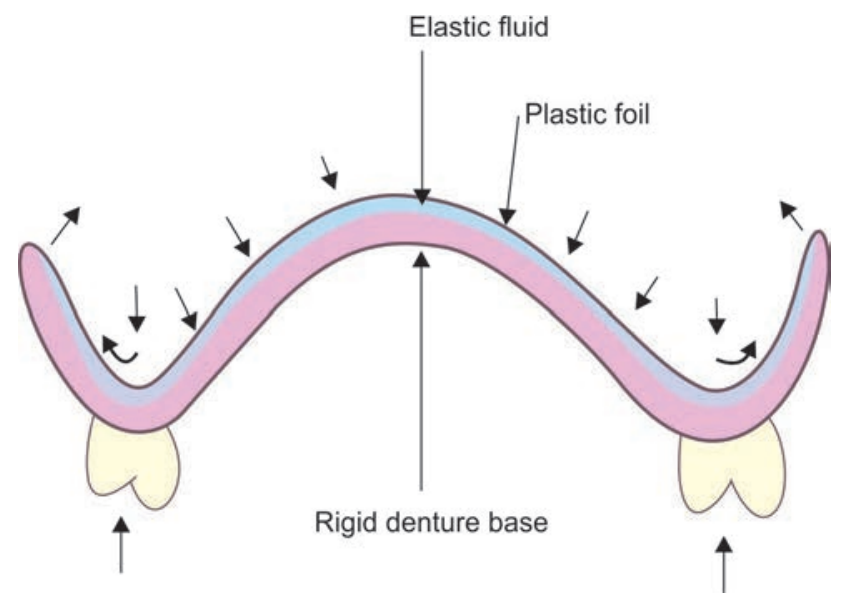

Fig. 16: Unidirectional loading of the denture resulting in multidirectinal distribution of hydrodynamic pressure throughout fluid and clasping pressure at its border (cross section)

irritation. In addition to biocompatibility, this sheet has excellent physical and mechanical properties. ${ }^{6}$

The adhesive used in this case is n-butyl-2-cyanoacrylate. It is also used in surgeries and as a protective covering over ulcers. ${ }^{7}$

Cushioning effect is rendered by glycerin in this case. The viscosity of glycerin ensures the desired inertia of the movement and, thus, improves stability. Glycerin is a clear, colorless, odorless liquid with good pharmaceutical placation. ${ }^{8}$ It has good thermal stability, water repellency, low surface tension, biocompatibility, low vapor pressure, and low cost. It is also used as a sweetening agent and preservative, and so it has proven in vivos afety.

\section{PRECAUTIONS}

- Thickness of the denture base should be at least $3 \mathrm{~mm}$.

- Seal should be perfect and should be checked for microleakage.

- Denture care instruction should be given to the patient. 
- In case the liquid leaks out, the patient should inform the dentist and the denture should be refilled.

- Repair is possible if the sheet gets ruptured and can be replaced over the preserved stone replica.

Advantages of liquid-supported denture over conventional denture ${ }^{10}$ :

- Preservation of residual ridge by optimal distribution of masticatory forces

- It provides close adaptation that enhances retention stability and comfort

- Optimized atmospheric pressure, adhesion, cohesion, and mechanical interlocking in undercuts

- Smooth flexible surface improves patient's tolerance and comfort

- Prevention of chronic sourness due to soft flexible denture base

- Liquid-supported dentures also help in alleviating problems arising from superficial mental nerve and inferior alveolar canal.

The drawback of liquid-supported denture is that the relining procedure is not possible.

Follow-up of the patients showed improved adaptation to these dentures over a period of time and problems arising from reduced masticatory functions improved. ${ }^{5}$

\section{CONCLUSION}

Severely resorbed ridges pose a prosthodontic challenge in achieving stability and retention for the prostheses.

Considering conventional prosthodontics, the use of liquid-supported dentures provides a cushion effect to the mucosa, which helps in equal distribution of forces that helps to minimize bone resorption and improves the comfort level of the patient.
Liquid-supported dentures are a conservative treatment, which fulfill MM Devan's dictum: "It is more important to preserve what already exists than to replace what is missing."

\section{REFERENCES}

1. Jain A, Puranik S, Jagadeesh MS, Kattimani P, Akki S, Kumar P, Laxmi V. Liquid supported dentures: a soft option - a case report. Case Rep Dent 2013 Feb;2013:4.

2. Dammani B, Singote $S$, Athavale $S$, Kakade D, Liquid supported denture: a gentle option. J Indian Prosthodont Soc 2007 Mar;7(1):35-39.

3. Pawah S, Gupta A, Madan B, Pathak C, Shukla P, Gupta P. Liquid supported dentures: a viable option for atrophic edentulous ridges. Indian J Dent Sci 2013 Dec;5(5):79-81.

4. Mody PV, Kumar G, Kumar M, Shetty B. Liquid supported denture - management of flabby ridges. Contemp Clin Dent 2012 Jul-Sep;3(3):323-325.

5. Dsouza KM, Aras MA. A conservative prosthodontic approach for the treatment of a patient with atrophic, flabby and unemployed edentulous ridges: a case report. Int J Clin Dent 2013 Jan;6(1):49-58.

6. Shamnur SN, Mehta V, Kumari N. An old wine in a new bottle-liquid supported denture for atrophic residual ridge. Ann Essences Dent 2012 Oct-Dec;4(4):85-88.

7. Padmaja S. Liquid-supported denture \& neutral zone for atrophic residual ridges: a case report. People's J Sci Res 2012 Jan;5(1):52-55.

8. Narula S, Meenakshi K, Hanada M, Garg D, Singh B, Lakhani D. Fluid retained dentures: a case report. Indian J Stomatol 2012;3(3):184-186.

9. Radke U, Mundhe D, Banerjee R. Cushioned dentures; a relief for the compromised tissue - a case report. J Indian Dent Assoc 2011 May;5(5):659-661.

10. Keni NN, Aras MA, Chitre V. Management of flabby ridges using liquid supported denture: a case report. J Adv Prosthodont 2011 Mar;3(1):43-46. 